ISCKMC 2020

International Congress on Academic Research in Society, Technology and Culture

\title{
STATE, CAUSES AND WAYS OF MINIMIZING FEMALE JUVENILE DELINQUENCY
}

\author{
Oksana Aleksandrovna Osadchuk (a)*, Aleksandr Vasilyevich Groshev (b), \\ Elena Evgenevna Ryabtseva (c), Zulfiya Zaletdinovna Ekimova (d) \\ *Corresponding author
}

(a) Sevastopol Economic and Humanitarian Institute (branch) of the Crimean Federal University named after V.I. Vernadsky, Sevastopol, Russia, ksufa2007@rambler.ru,

(b) Federal State Budgetary Educational Institution of Higher Education «Kuban State Agrarian University named after I.T. Trubilin» (FSBEI HE Kuban SAU.), Russian Federation, Krasnodar, groshevav54@gmail.com,

(c) Sevastopol Economic and Humanitarian Institute (branch) of the Crimean Federal University named after V.I. Vernadsky, Sevastopol, Russia, segicfu@mail.ru,

(d) Sevastopol Economic and Humanitarian Institute (branch) of the Crimean Federal University named after V.I. Vernadsky, Sevastopol, Russia, segicfu@mail.ru

\begin{abstract}
This article provides an analysis of the characteristics of modern female juvenile delinquency, which makes it possible to understand what this problem is, to determine the general patterns and trends characteristic of it, to identify the causes of its occurrence and some directions and measures of its prevention and prevention. The article analyzes the empirical data obtained by questioning various categories of respondents. The analysis of the data allows, within the framework of this study, concluding the significance of this problem for society, the main reasons for asocial and delinquent deviations in adolescent girls, the influence of various factors of socialization on the criminal behaviour of female minors, and the motivation of their criminogenic activity. The study allows stating that among the preventive measures that can reduce the level of adolescent female crime, the priority ones are: early detection of dysfunctional families, control over attendance at educational institutions and psychological correction of asocial adolescents. In order to reduce the level of neglect of minors, it is proposed to introduce into the administrative legislation a norm on the responsibility of parents, whose children miss classes without good reason. Special attention is paid to the improvement of the norms of the Criminal Code of the Russian Federation on the criminal responsibility of minors. In particular, in order to make the application of the institution of compulsory measures of educational influence more effective, it is proposed to expand the list of their types and grounds for the application to juvenile offenders.
\end{abstract}

2357-1330 C 2021 Published by European Publisher.

Keywords: Female juvenile delinquency, prevention, coercive measures 


\section{Introduction}

Women's crime as a whole reflects the level of the moral health of society, its spirituality, attitude to generally accepted human values. It has a negative impact on society, its institutions, family, in general, on the socio-psychological atmosphere. The criminal behaviour of female minors is a symbiosis of female delinquency and juvenile delinquency. Therefore, this problem deserves an independent study in order to identify its specific features and preventive measures.

\section{Problem Statement}

The development of the most effective methods of preventing female juvenile delinquency requires researching the current state and trends of this type of crime, identifying the leading causes of this negative phenomenon and revealing the criminological features of its prevention.

\section{Research Questions}

The subject of the research is female juvenile delinquency, the conditions and patterns of its existence and development, as well as ways to minimize this type of juvenile delinquency.

\section{Purpose of the Study}

The purpose of the study is to identify the shortcomings of legal regulation of measures of criminal responsibility and prevention of juvenile delinquency and their implementation and to suggest possible ways to eliminate them. The implementation of this goal is possible based on an analysis of the current state, trends and factors that give rise to female juvenile delinquency, as well as the current legislation and practice of its application.

\section{Research Methods}

The methodological basis of the research was formed by formal-logical, sociological and statistical general scientific methods of cognition, as well as the method of comparative jurisprudence.

\section{Findings}

The effectiveness of the fight against any negative social manifestations largely depends on how much society is ready to perceive them as a social problem. This fully applies to such a destructive phenomenon as juvenile delinquency, including female sex.

It should be noted that until relatively recently, there was no gender approach in the statistical accounting of juvenile delinquency. That is, female minors committed crimes along with young men, but this type of crime did not stand out as an independent one. Only after the adoption of new criminal procedural legislation in the Russian Federation at the beginning of the 2000s and changes in the crime 
registration system, information on the state and dynamics of this type of crime became available, which made it possible to obtain empirical material for research.

Today, female juvenile delinquency is characterized by stable quantitative indicators with a tendency to increase the degree of its public danger due to the commission of more and more severe crimes by this category of criminals, including group and violent crimes. So, as of 2019, 3846 female minors were brought to criminal responsibility in the Russian Federation for committing various crimes, which amounted to $10.13 \%$ of the indicators of all juvenile delinquency for the specified period. One thousand three hundred twenty-five girls were sentenced to various types of punishments, that is, $34.45 \%$ of all those brought to justice, with an evident predominance of grave crimes in the structure of committed criminal acts -603 out of 1,325 , respectively, that is, $45.51 \%$. The indicator of especially grave crimes of minors is also significant $-9.73 \%$. At the same time, almost half, namely $40.75 \%$ of the crimes, convicted minor girls committed in a group, including in 227 cases with the complicity of adults (17.13\%). In 996 cases (75.17\%), female minors were convicted of crimes against property, among which the theft with aggravated and especially aggravated circumstances prevailed, 674 (67.67\%), respectively. In 283 cases (21.36\%), convicts committed violent crimes, seemingly uncharacteristic for females, such as murders $(1.14 \%)$, bodily injuries of varying severity $(3.85 \%)$, beatings $(3,63 \%)$. Of all convicted underage girls, 46 (3.47 \%) committed the crime again (Osadchuk \& Groshev, 2019).

The above statistical data leave no doubt not only of the existence of female juvenile delinquency as a systemic negative social phenomenon but also convinces of dangerous trends in its development. At the same time, it is necessary to take into account the high level of latency of the analyzed type of crime, which is explained mainly by the slight nature of the crimes committed and the loyalty of the victims to the juvenile offender.

A similar situation against the background of a general increase in the level of juvenile delinquency is noted by researchers in the countries of near and far abroad (Cauffman, 2008; Chiang et al., 2020).

It seems that the problem is relevant not only because girls (women), in principle, are carriers of the country's gene pool, their role in the functioning of the family, as a unit of society, is difficult to overestimate, and, therefore, personal degradation entails negative consequences not only in small social groups but also in society as a whole (Osadchuk, 2018). Besides, a girl with antisocial behavioural attitudes negative influence on her peers, acting as a catalyst for the negative behaviour of this category of potential offenders. The desire for self-affirmation in a specific group of peers entails the need to assimilate accepted in it, not always socially approved, stereotypes of behaviour, which against the background of puberty and gender self-identification of adolescents can lead to various asocial and delinquent deviations (Liu \& Miller, 2020). Juvenile criminals, often because of early and promiscuous sexual relations, join the contingent of mothers who lead an immoral lifestyle and neglect their parental responsibilities (Kupriyanova, 2013). Finally, the crime of the future is recruited from minors. As many researchers note (Ilyashenko, 2000; Kupriyanova, 2013), the majority of female criminals began their criminal path precisely at a minor age.

Thus, there is not only the actual existence but also the socially dangerous nature of female juvenile delinquency. It should be noted that society takes quite seriously the whole range of threats 
associated with this destructive phenomenon. A survey of public opinion was carried out by questioning different categories of respondents, including minors in senior classes of secondary schools, adults of different age categories, senior teachers and employees of the minors' affairs units of the Internal Affairs Directorate. This study allowed identifying some patterns characteristic of the analyzed segment of crime and draw several conclusions.

Thus, when asked about the urgency of the problem of juvenile delinquency, including the female sex, the majority of respondents among the adult population (54.61\%), adolescents $(39.42 \%)$ and senior schoolteachers (36.66 \%) identified the problem of delinquency among adolescent girls unambiguously relevant and answered the question in the affirmative, which indicates a fairly high interest in the topic raised. Consequently, these respondents, either personally or through their social circle, encountered antisocial behaviour of female minors. An unequivocally negative answer to the question was expressed by $2.13 \%$ of adult respondents, $17.31 \%$ of adolescents and $16.67 \%$ of high school teachers surveyed.

When asked about the reasons for female juvenile delinquency, the majority of respondents among teachers indicated insufficient parental control (40.0\%), the influence of adults involved in illegal activities $(30.0 \%)$ and poor living conditions $(30.0 \%)$. These indicators point to the significant role of parents in the education and prevention of juvenile delinquency.

The assumption that the main reasons are weak living conditions and material distress, which can be attributed to material (household) factors, were expressed, respectively, by $30.0 \%$ and $26.6 \%$ of respondents, which in total is more than $56 \%$. See Fig. 01 for more information.

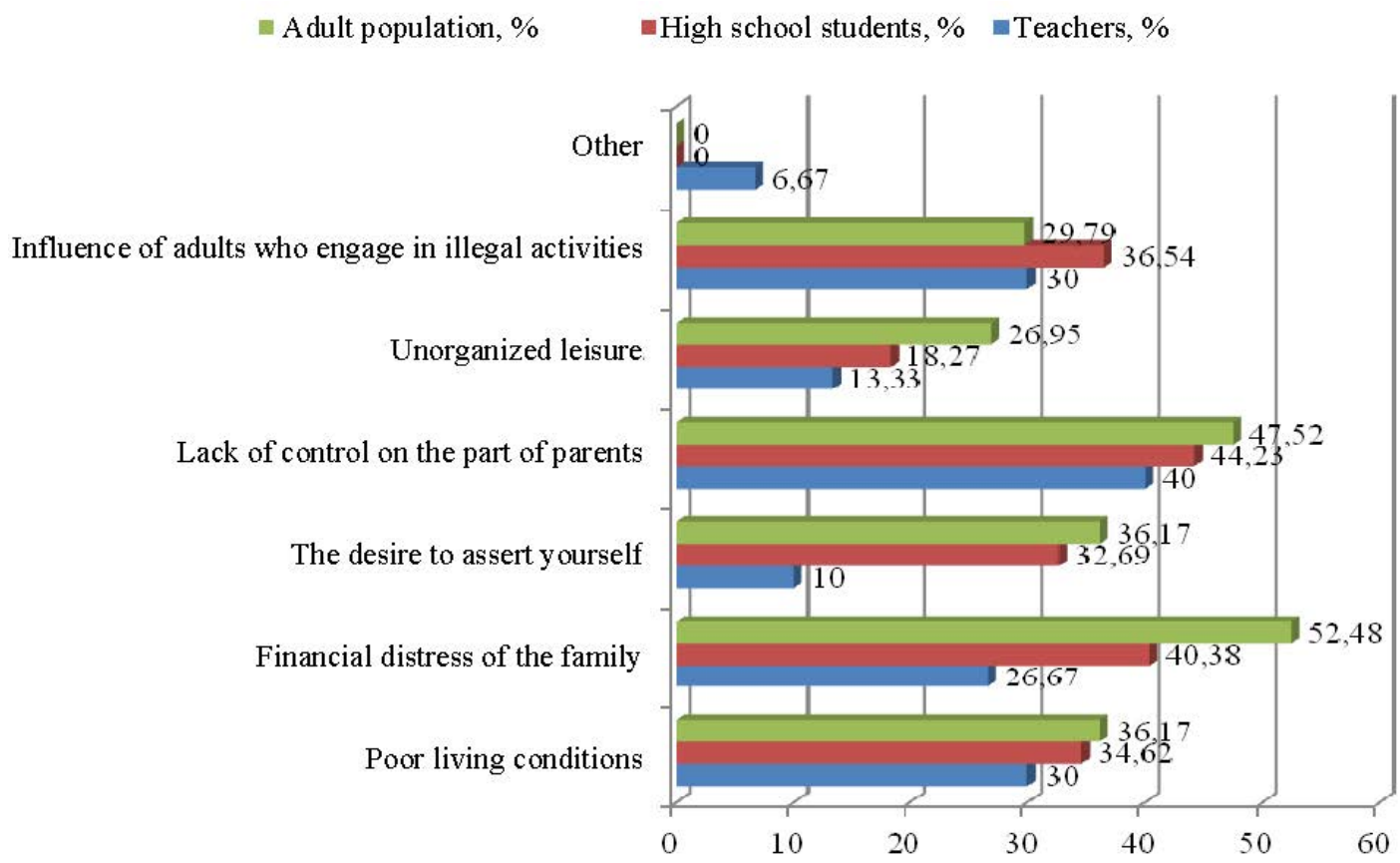

Figure 1. Distribution of answers of respondents of all groups of respondents to the question "What is the main cause of juvenile delinquency, including female crime?"

Among the most popular answers among high school students were the reasons associated with insufficient parental control (44.3\%) and material disadvantage of the family (40.38\%), as well as poor 
living conditions (34.62 \%). Among the main reasons, the adult population also sees material distress in the family $(52.48 \%)$ and insufficient parental control (47.52 \%). It should be noted that all groups of respondents indicated several answers; that is, they see the reason for the crime as a consequence of many factors.

When asked what makes underage girls break the law for the first time, more than $65 \%$ of all groups of respondents believe that for the first time already formed asocial inclinations influence the commission of a crime by underage girls. On average, among all groups of respondents in second place (about $30 \%$ ) believe that the current favourable crime situation is a reason for underage girls to break the law for the first time. At the same time, the absolute majority of respondents indicated that asocial inclinations are formed in adolescent girls in the circle of friends and acquaintances, mainly in high school $(50 \%)$.

Table 1. Distribution of the answers of the respondents of all target groups to the question: "In what area, in your opinion, the criminal tendencies of a teenage girl are mostly formed?"

\begin{tabular}{ccccccc}
\hline Answer & \multicolumn{2}{c}{ Teachers } & \multicolumn{2}{c}{ High school students } & \multicolumn{2}{c}{ Adult population } \\
\hline & Answers & $\%$ & Answers & $\%$ & Answers & $\%$ \\
\hline In family & 10 & 33.3 & 13 & 12.5 & 28 & 19.86 \\
At school & 2 & 6.67 & 9 & 8.65 & 28 & 19.86 \\
Among friends and & 26 & 86.67 & 84 & 80.77 & 113 & 80.14 \\
acquaintances & & & & & 1 & 0.71 \\
Other & 0 & 0.0 & 3 & 2.88 & 170 & - \\
Total & 38 & - & 109 & - & & \\
\hline
\end{tabular}

The majority of respondents named self-assertion as the primary motive for committing a crime by a minor, respectively, $36.67 \%$ of surveyed teachers, $59.62 \%$ of high school students, $54.61 \%$ of the adult population. Also, the respondents note the prevalence of the selfish motive of the illegal behaviour of underage girls, in its most varied variations, combined with hatred, envy, jealousy, greed-moneygrubbing, anger, revenge. In this case, motivation is simultaneously the result of the deformations that have occurred in the personality of the criminal and the cause.

It should be noted that the motivation as mentioned above for the unlawful behaviour of underage girls is imposed on disregard for the norms of morality and ethics, the rules of behaviour in society, and finally, their legal nihilism.

Table 2. Distribution of answers of respondents of all target groups to the question "What, in your opinion, are the motives for committing crimes by teenage girls?"

\begin{tabular}{ccccccc}
\hline Answer & \multicolumn{2}{c}{ Teachers } & \multicolumn{2}{c}{ High school students } & \multicolumn{2}{c}{ Adult population } \\
\hline & Answers & $\%$ & Answers & $\%$ & Answers & $\%$ \\
\hline Greed & 10 & 33.33 & 15 & 14.42 & 38 & 26,95 \\
Envy & 11 & 36.67 & 48 & 46.15 & 64 & 45,39 \\
Revenge & 8 & 26.67 & 54 & 51.92 & 55 & 39,01 \\
$\begin{array}{c}\text { Self-affirmation } \\
\text { Committed to meeting prestigious }\end{array}$ & 11 & 36.67 & 62 & 59.62 & 77 & 54,61 \\
$\begin{array}{c}\text { needs } \\
\text { A misunderstood sense of }\end{array}$ & 10 & 33.33 & 29 & 27.88 & 52 & 36,88 \\
$\quad$ camaraderie & 0 & 0 & 18 & 17.31 & 44 & 31,21 \\
Compassion & & & & & & \\
Other & 10 & 3.33 & 0 & 0 & 8 & 5,67 \\
Total & 2 & 6.67 & 0 & 0 & 0 & 0 \\
& 53 & - & & 226 & 338 & - \\
\hline
\end{tabular}


An analysis of the answers to the question of what factors contribute to the formation of criminal inclinations in female minors to a greater extent showed that smoking, drug use, alcohol use is the most popular among all groups of respondents (from 50 to $70 \%$ ), as well as a significant factor criminal inclinations, are contacts with previously convicted persons, a negative example of parents (from 25 to $50 \%$ ). In this case, it should be noted that all these factors of negative influence on the behaviour of a teenager are closely interconnected and condition each other. So, in families that allow socially disapproving behaviour (assault, drunkenness, sexual promiscuity), adolescents at an earlier age become involved in smoking, drinking alcohol, allow themselves a violent way of resolving conflicts, previously convicted persons complement the degradation of a teenager who has fallen into the circle of communication by engaging in the personal criminal experience.

Among the effective measures for the prevention of juvenile delinquency, the majority of respondents see early detection of dysfunctional families (from 55-70\% of respondents). Also, among the popular answers, there is an individual help from a psychologist (about $43 \%$ of the respondents). Note that high school students and the adult population see in solving the problem such a measure as school control over school attendance (about $40 \%$ of respondents). High school teachers, on the other hand, ranked third as a preventive measure - toughening the criminal liability of minors $(36.6 \%$ of respondents). The given data indicate the natural interdependence of measures for the prevention of juvenile delinquency. So, the first signal about the trouble in the family and the lack of control of a teenager are absences from school without good reason. This circumstance makes it possible to identify these families with their registration, with the parallel provision of psycho-corrective assistance to a teenager.

The conducted research allows stating that, in general, society adequately assesses the state, causes, conditions and measures for the prevention of juvenile delinquency, including female delinquency, focusing on the role of the family and school in its minimization. One of the reasons contributing to the commission of unlawful acts by adolescents is neglect, the lack of parental control over the attendance of minors in educational institutions. In this regard, the experience of Germany in solving this issue deserves attention (Obydennova, 2016). There is a practice of bringing parents to administrative responsibility in the form of a fine for absenteeism by their children from school. Indeed, the state provides citizens with free general education, invests considerable budgetary funds in the education system, and enshrines in the Constitution the obligation of parents to ensure that their children receive basic general education (paragraph 4 of Article 43). There are all the prerequisites for the application of property sanctions for failure to fulfil this obligation.

Therefore, in the case of imposing a compulsory measure on reinstatement (admission) at school, it is proposed to fix in the Code of Administrative Offenses of the Russian Federation No. 195-FZ dated 30.12.2001 (as amended on 24.04.2020) a measure of parental responsibility in the form of an administrative fine for failure to comply with it (omissions classes). It seems that such an approach will help to reduce the level of neglect of minors, and as a result, juvenile delinquency.

An essential role in the prevention and prophylaxis of juvenile delinquency, including that of women, is played by an adequate normative consolidation of the peculiarities of juvenile criminal 
responsibility and its full implementation in practice. Both that and another today cause fair criticism of researchers.

Thus, the institution of releasing minors from criminal liability with the use of compulsory educational measures, namely the list of such measures and the grounds for their application, requires its improvement.

In particular, it seems necessary to supplement Article 90 of the Criminal Code of the Russian Federation with such compulsory measures of educational influence as

- the obligation to comply with the instructions on the place of stay;

- in a family or a social institution;

- enrol (recover) to study;

- compulsory involvement of a minor in work.

In connection with the decrease in the age of drug addiction and alcoholization of the population, it would be relevant to include in the list of compulsory educational measures for adolescents the obligation to undergo examination and treatment for alcohol (drug) addiction. Also, when an adolescent displays aggressive behaviour or commits a violent crime, it is advisable to provide for such a compulsory measure as the obligation to undergo a course of psycho-correction of behaviour.

The legislator focuses on the degree of public danger of the committed crime, limiting himself to crimes of small and medium gravity when he determines the conditions for the application of compulsory measures of educational influence. At the same time, in contrast to the general grounds for exemption from criminal liability, it is legally indifferent to the first time or not for the first time that a minor offender has violated the law. This situation seems illogical since if a teenager repeatedly violated the criminal law prohibition, this indicates an increase in asocial behavioural habits and further deformation of his legal consciousness, which in turn indicates the ineffectiveness of coercive measures of educational influence applied after the first one. Repeated application of these measures to the same offender in cases of repeated commission of crimes seems inappropriate since this can form in him a sense of impunity and a nihilistic attitude towards the criminal law, therefore, in this matter, it is worth limiting ourselves to cases of committing a crime for the first time.

Also, it seems that the above measures should be applied not only to minors who have committed crimes of small or medium gravity but also to minors who have committed a severe crime for the first time, not associated with the onset of severe consequences. Thus, it is proposed to limit the possibility of using coercive measures of educational influence provided for in Part 1 of Article 90 of the Criminal Code of the Russian Federation, only by crimes committed for the first time, while simultaneously expanding the possibility of their application to minors who have committed a serious crime in cases of involvement in its commission by an adult accomplice.

\section{Conclusion}

Based on the study, we can conclude that female adolescent crime has its characteristics and can be distinguished as a separate object of criminological research. These features are associated with gender, age, mental differences in the personality of minors. Female teenage delinquency develops under the influence of the same factors as a crime in general. An essential role in the formation of the deviant 
behaviour of female minors is played by neglect and idle pastime, early alcoholism and drug addiction, sexual promiscuity. The cause and at the same time, the consequence of such behaviour are a disregard for morality and ethics, the rules of the community and legal nihilism and legal irresponsibility.

An essential aspect in the prevention of crime against female minors is the elimination of detrimental phenomena, under the influence of which the formation of criminogenic motivation occurs. The effectiveness of the implementation of the measures for the prevention and prevention of juvenile delinquency, including that of women, can be facilitated by the introduction of administrative responsibility of parents for systematic adolescent absenteeism from school classes (if an appropriate measure of educational influence is applied), as well as improving the criminal-legal institution of compulsory educational measures.

\section{References}

Cauffman, E. (2008). Understanding the Female Offender. The Future of Children, 18(2), 119-142.

Chiang, C. -J., Yu, C., Chen, H. -S., \& Johnson-Reid, M. (2020). Social bonds and profiles of delinquency among adolescents: Differential effects by gender and age. Children and Youth Services Rev., 110, 104751.

Ilyashenko, A. N. (2000). Criminality of female minors: state, reasons, prevention. Voronezh Inst. of the Ministry of internal Affairs of Russ.

Kupriyanova, A. V. (2013). Women's juvenile delinquency (regional characteristics): monograph. ChitaZabgu.

Liu, L., \& Miller, L. S. (2020). Protective factors against juvenile delinquency: Exploring gender with a nationally representative sample of youth. Soc. Sci. Res., 86, 102376.

Obydennova, T. V. (2016). On the issue of using the positive experience of Germany in the sphere of prevention of offenses among minors in Russia. Administr. and municipal law, 1, 81-87.

Osadchuk, O. A. (2018). State, dynamics and causes of criminality of female minors in the Russian Federation (Federal and regional level). Ethnosocium and interethnic culture, 9(123), 117-123.

Osadchuk, O. A., \& Groshev, A. V. (2019). Current state and main trends in juvenile delinquency of female minors. Law and practice, 4, 94-98. 